\title{
ORAL HEALTH CONDITION, STATUS OF HYGIENE AND FOOD HABITS IN CHILDREN UNDERGOING ANTICANCER THERAPY
}

\author{
Daria Pietraszewska, Lidia Postek-Stefańska, Danuta llczuk-Rypuła \\ Department of Pediatric Dentistry, Medical University of Silesia, Katowice, Poland
}

\begin{abstract}
INTRODUCTION: Anticancer treatment is a challenge for children themselves, as well as for their guardians and medical personnel; it is associated with numerous side effects of the implemented therapy such as neutropenia, mucositis, taste disorders, nausea, and lack of appetite affecting the condition of oral cavity.

ОвјестіvEs: The authors want to estimate the oral health care condition in young patients undergoing anticancer treatment and analyze the self-reported hygiene and food habits.

MATERIAL AND METHODS: Dental examinations were conducted in children treated in the Oncology, Hematology and Chemotherapy Ward. Intraoral examination was conducted in the artificial light and a disposable diagnostic set. The oral cavity hygiene was defined by means of the plaque index (PI) indicator by Silness and Löe and the Simplified Oral Hygiene Index (OHI-S) according to Greene and Vermillion only in patients with mixed or permanent dentition. A short survey was also done, with questions about the eating habits and hygienic habits of a patient (frequency of brushing teeth, kind of toothpaste, additional oral cavity hygiene substances and fluoride prevention program). The last part of the survey comprised questions associated with a patient's subjective feelings.

RESULTS: The value of the PI indicator in the examined children was 0.75. The average value of the DI-S component of the OHI-S was 0.84 . The survey examination revealed that $97 \%$ of the children used a toothpaste with fluoride. Additional means of maintaining oral cavity hygiene were followed by $50 \%$ of the examined patients. Only $9 \%$ of the patients have a habit of quenching their thirst with water.

ConcLusions: In the light of the presented results, it seems necessary to undertake further systemic measures aiming to improve the oral hygiene condition of children undergoing cancer therapy and the education level of parents on the subject of diet.
\end{abstract}

KEY wORDs: children's chemotherapy, oral hygiene, food habits, plaque index, OHI-S.

J Stoma 2021; 74, 3: 166-171

DOI: https://doi.org/10.5114/jos.2021.109184

\section{INTRODUCTION}

Anticancer treatment is a challenge for children themselves, as well as for their guardians and medical personnel; it is associated with numerous side effects of the implemented therapy, which also applies to the oral cavity area.
In Poland there are 1,100 to 1,200 new cases of cancer in children below 17 years of age each year, which results in 140 to 145 new cases per million children. $26 \%$ of cases concern blood cancer, $22 \%$ CNS [1]. Cancer cases contribute to $5.4 \%$ of deaths in boys and $6.4 \%$ of deaths in girls [2]. For obvious reasons, it is logical

\section{JOURNAL OF} STOMATOLOGY

AdDRESS FOR CORRESPONDENCE: Dr. Daria Pietraszewska, Department of Pediatric Dentistry, Medical University of Silesia in Katowice, Traugutta sq. 2, 41-800 Zabrze, Poland, e-mail: dpietraszewska@sum.edu.pl 
why parents are concentrated on treating the underlying disease, which leads to ignoring the aspects associated with oral health care. Taste disorders, nausea, lack of appetite, all linked to the therapy, may incline the guardians to offer the sick children highly processed products, sweet snacks and fizzy drinks according to the principal that a child should eat in the first place. The situation may get yet more complicated owing to the psychological state of the parents $[3,4]$ and their professional situation [5]. Their reaction to the cancer diagnosis concerning their child and the fact the children are forced to undertake a therapy with numerous side effects may contribute to that.

One side effect is mucositis [6-9], whose appearance almost totally disables the patients from taking oral health care and eating meals. In the period of neutropenia, a severe complication resulting from the applied chemotherapy, patients refrain from brushing their teeth, which additionally negatively contributes to the condition of the teeth, gingivae and mucous membrane $[10,11]$.

\section{OBJECTIVES}

The purpose of this article is to estimate the oral health care condition in young patients undergoing anticancer treatment and the analysis of the declared hygiene and food habits.

\section{MATERIAL AND METHODS}

Dental examinations were conducted in children treated in the Oncology, Hematology and Chemotherapy Ward of John Paul II Silesian Health Centre, Katowice. 58 patients participated in the examination (38 boys, i.e. $66 \%$, and 20 girls, i.e. $34 \%$ ). The study was conducted while on treatment. No child has completed oncological therapy. Every patient was in general stable health. The parents have given a written consent for their child to participate in the examination, having become acquainted with the assumptions and aims of the project. In a patient's card the following information was noted down: first name, surname, age on the day of the examination, age when the disease was diagnosed, oncological diagnosis, the medicine taken, which cycle of therapy a child goes through, whether radiotherapy was applied, in which area, the current blood test results, including morphology with blood smear.

Intraoral examination was conducted in artificial light, using a headlight and a disposable diagnostic set (a probe and a mirror).

Oral cavity hygiene was defined by means of the plaque index (PI) indicator by Silness and Löe [12], by examining the presence of bacterial plaque on the buccal and lingual surfaces, as well as on tangent teeth 16 , $11,24,31,36,44$ and by examining the thickness of soft deposits according to the following scale:
- 0 - no plaque,

- 1 - a thin layer of plaque diagnosed with a probe, but otherwise invisible,

- 2 - moderate bacterial plaque concentration, visible,

- 3 - rich bacterial plaque concentration on the tooth surface.

To estimate bacterial plaque retention the OHI-S was used according to Greene and Vermillion [13], which consists of two components: the soft debris index (DI-S) and the calculus index (CI-S) using the following estimation criteria:

- 0 - no debris, no calculus;

- 1 - presence of soft debris or supragingival calculus that covers up to $1 / 3$ of the teeth surface;

- 2 - presence of soft debris and supragingival calculus that covers up to $2 / 3$ of the surface of the examined tooth or the occurrence of single instances of subgingival calculus around the tooth's neck;

- 3 - presence of debris or supragingival calculus that covers up to $2 / 3$ of the tooth's surface or a wide stripe of subgingival calculus around the tooth's neck.

Due to the fact that no trace of calculus was found in any of the patients, the DI-S component was solely used.

The simplified OHI-S was applied to examine the following teeth: $11,16,26,36,31,46$. In upper molars, the buccal surface was estimated and in lower molars and incisors, the labial surface was estimated. The numerical value of the component is within 0 to 3 . The estimation criteria were as follows:

- 0 - very good hygiene of oral cavity,

- 0.1-0.6 - good hygiene of oral cavity,

- 0.7-1.8 - satisfactory hygiene of oral cavity,

- 1.9-3.0 - poor hygiene of oral cavity.

PI index and OHI-S were determined only in children with permanent dentition.

A short survey was also done, where questions about the eating habits were asked (the kind of drinks drunk, whether there is a habit of night drinking or night eating by a child) and the hygienic habits of a patient, i.e. how frequently they brush their teeth, whether they use a toothpaste with fluoride, whether they apply any additional oral cavity hygiene substances, whether they participated in a fluoride prevention program, either individual or common. The last part of the survey comprised questions associated with a patient's subjective feelings as to their oral cavity, which may accompany the treatment where cytostatics are applied, such as a burning sensation, difficulties in eating and swallowing food, taste disorders, oversensitivity to certain products, difficulties in speaking, dryness or salivation. There were also cases of vomiting as a reaction to the applied chemotherapy.

\section{RESULTS}

The patient's average age at the time of the examination was 9.5 years, whereas the average age at the time of the 
TABLE 1. Types of cancer cases in the examined children

\begin{tabular}{|l|c|c|c|}
\hline Diagnosis & Overall & Boys & Girls \\
\hline ALL (acute lymphocytic leukemia) & 13 & 8 & 5 \\
\hline ANLL (acute nonlymphocytic leukemia) & 2 & 2 & 0 \\
\hline Tumors CNS & 18 & 10 & 8 \\
\hline Sarcoma & 11 & 6 & 5 \\
\hline Lymphoma & 8 & 7 & 1 \\
\hline Nephroblastoma/Wilms' tumor & 2 & 2 & 0 \\
\hline Retinoblastoma & 1 & 1 & 0 \\
\hline Neuroblastoma & 1 & 0 & 1 \\
\hline Histiocytosis & 1 & 1 & 0 \\
\hline Testicular cancer & 1 & 1 & - \\
\hline
\end{tabular}

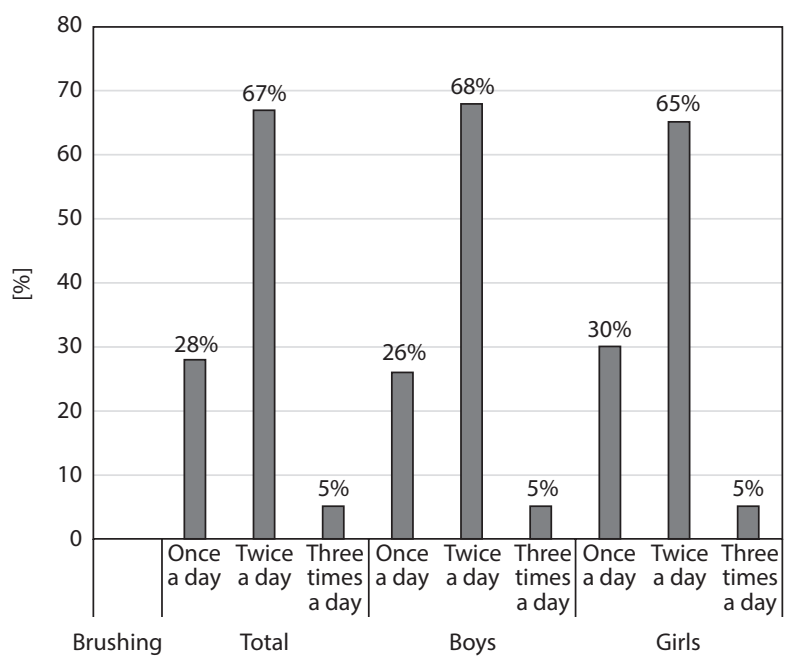

FIGURE 1. The frequency of teeth brushing during the day

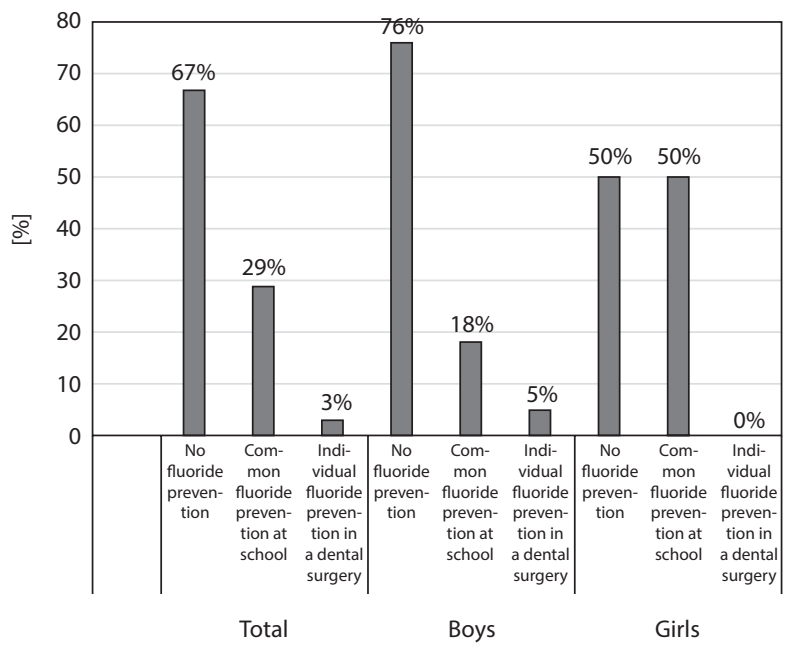

FIGURE 2. Fluoride prevention programme

cancer disease diagnosis was 8.4 years. The youngest child at the time of the examination was 3.3 and the oldest was 17.11 years old. At the time of the diagnosis the youngest patient was 1.6 whereas the oldest one was 17.9 years old.
The kind of cancer the patients suffered from when they took part in the examination is presented in Table 1. The blood parameters of the patients were as follows: 39 patients had a proper level of blood cells, adequate for a patient undergoing chemotherapy and without a significant shortfall, 1 patient suffered from anemia, 3 suffered from neutropenia and thrombocytopenia, the following 5 from leucopenia, 2 from neutropenia, 7 from leucopenia and thrombocytopenia, 1 from neutropenia and accompanying anemia.

On average the patients underwent 5 cycles of chemotherapy ( 4 cycles for boys and 6 for girls). 13 patients, i.e. $12 \%$, underwent radiotherapy, most frequently either of the head or the spinal canal.

There was no effect of diagnosis of a specific neoplasm on the oral hygiene status.

The value of the PI index indicator in the examined children was 0.75 ( 0.79 for boys and 0.71 for girls). The average value of the DI-S component of the OHI-S was 0.84 ( 0.89 for boys and 0.79 for girls).

The survey examination revealed that $97 \%$ of the children used a toothpaste with fluoride.

The remaining persons use a toothpaste without fluoride or simply a moist toothbrush. $67 \%$ of the patients brush their teeth twice a day, $5 \%$ do it three times a day, whereas $28 \%$ of children brush their teeth once a day or not at all (Figure 1).

No preventive therapy was applied in $67 \%$ of the patients. $29 \%$ of children participated in the common fluoride prevention program. This therapy took place before the hospital treatment. In contrast, individual preventive therapy in a dental surgery was used by $3 \%$ of the patients (Figure 2).

The additional means of maintaining oral cavity hygiene by $50 \%$ of the examined patients of the oncology ward was dental floss, reported by $3 \%$. An interdental irrigator is used only by $5 \%$ of girls ( 1 person) and none of the boys. An antibacterial liquid is used by $12 \%$ of the children, whereas Alfa Med solution is used by $33 \%$ of the examined patients (Figure 3 ).

$47 \%$ of the patients stated that during the anticancer therapy they had at least one episode of fungal infection within oral cavity. Vomiting accompanied the treatment of $45 \%$ of children. A burning sensation in the oral cavity occurred in $21 \%$ of the patients. Difficulties in swallowing and acquiring food were reported by $28 \%$ of the patients. Taste disorders were experienced by as many as $64 \%$ of those questioned. Oversensitivity to some food was reported by $24 \%$ of the patients and $17 \%$ of the children had difficulties in speaking. The feeling of dryness in the mouth associated with the anticancer treatment was experienced by $29 \%$ of the patients, whereas salivation was mentioned by $10 \%$ (Figure 4 ).

Only $9 \%$ of the patients have a habit of quenching their thirst with water; the remaining 91\% use fruit juice, sweetened tea, fizzy drinks or flavored water, and $22 \%$ of the patients admitted they have a habit of either 
being give night drinks by parents or getting them themselves (Figure 5).

\section{DISCUSSION}

The condition of the oral cavity in the examined children treated for cancer was estimated by means of the OHI-S (DI-S component); in the present examination it was at the level of 0.84 , whereas PI index was 0.75 (insufficient hygiene); Pels et al. achieved better results in chemotherapy [14] - they estimated the hygiene level by means of OHI-S to be 0.68 and by means of PI index to be 0.61 . Olczak-Kowalczyk et al. [15] observed worse hygiene condition in their examinations with the OHI-S at 1.88, whereas Venkataraghavan et al. [16] recorded a bad hygiene level in the examined group at 1.17 (OHI-S). Bardellini et al. [17] observed that the OHI-S value varied depending on the recommended toothpaste. In the group of hospitalized children who used a mild toothpaste with lysozyme, lactoferrin and lactoperoxidase, the factor reached 0.5 , whereas in the group using a toothpaste with fluoride (without menthol), OHI-S was 1.6.

A lot of authors underline potential serious consequences associated with the presence of dental plaque, whose bacteria may be the source of sepsis in patients after a marrow transplant [18]. Ponce-Torres et al. recorded the symptoms of gingivitis in association with dental plaque in $91.84 \%$ of children who underwent chemotherapy [19]. Nemeth et al. [25] observed the presence of soft deposits in $81.5 \%$ of children during chemotherapy.

Insufficient hygiene largely stimulates the occurrence of the symptoms of mucositis and the discomfort in the oral cavity that accompanies it, and this state does not correlate with the kind of anticancer medicine applied [20]. Avoiding brushing and other hygienic preventative measures owing to pain in the period of intensified mucositis recorded in the present examination was also observed by other authors, who recommend, in such difficult moments, using a sterile swab or a sponge that is soaked with 0.12 chlorhexidine solution [21-23, 27] for hygienic purposes within the oral cavity. It is however less efficient than brushing [27]. Cleansing with such a solution according to some authors does not significantly reduce the risk of streptococcal bacteraemia in patients after marrow transplant [24]. Yet, according to others, by reducing the number of pathogenic bacteria, it influences the reduction of the number of bacteraemia cases in children undergoing anticancer therapy [20]. Doss and coworkers underline, however, that chlorhexidine does not contribute to the elimination of dental plaque [18]. In examinations by Bardelini et al. even in the case of mucositis that accompanied chemotherapy, the patients did not abstain from brushing their teeth provided they used a toothpaste with lysozyme, lactoferrin and lactoperoxidase [17].

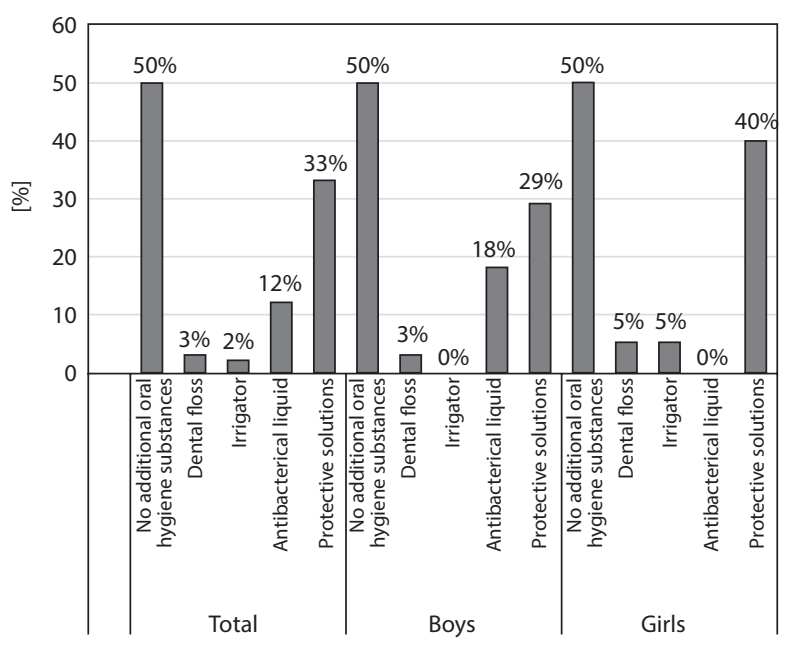

FIGURE 3. Applying additional oral hygiene methods

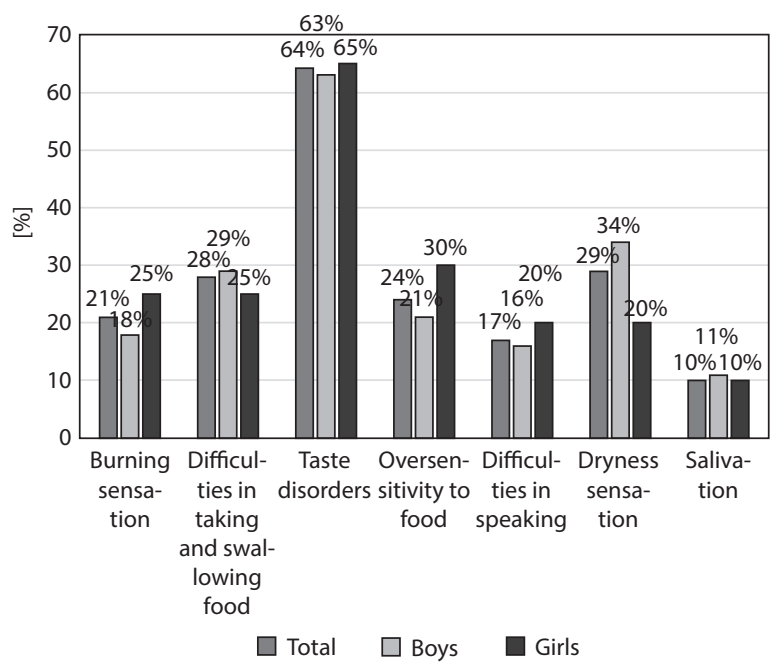

FIGURE 4. Patient's subjective feelings as to the oral cavity area during the chemiotherapy

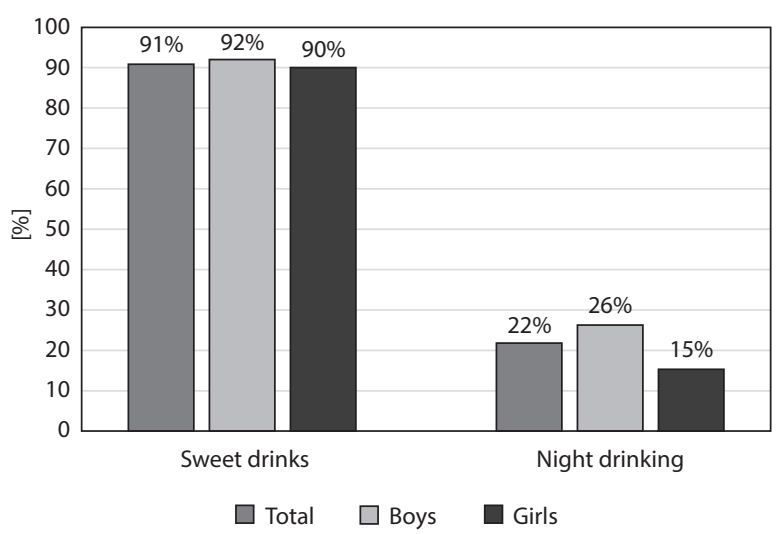

FIGURE 5. The drinking habits

Some authors $[23,26]$ recommend using mild cleansing solutions in the period of the intensification of inflammatory changes in the oral cavity, and, where possible, brushing after each meal (very difficult in practice) 
or using a toothpaste without SLS (sodium lauryl sulfate), which irritates the mucous membrane of the oral cavity.

To maintain proper hygiene in the oral cavity in children during the period of anticancer treatment, both parents' and guardians' cooperation and engagement is indispensable [27]. What could be of great assistance is a clear collection of guidelines (with a periodical checkup if they are truly followed) applied at the British centers of child oncology [28] that would stipulate the standards of dental care in patients diagnosed with cancer during and after cancer treatment with the instructions for parents and children on oral cavity hygiene. This information should be communicated by a nurse, a designated member of the personnel responsible for oral cavity hygiene. Before the treatment starts a survey should be done and the oral cavity condition of the patient estimated. Still, in the current health service in Poland such a course of action would be hard to implement. A similar protocol of hygiene is also missing from the Portuguese centers of child oncology [29], where there was revealed a significant discrepancy between oncological patients allegedly referred for dental treatment by nurses (100\%) and the parents' confirmation of only $23 \%$ of such cases.

Educating parents and children on the importance of dental care and the possibilities of minimizing discomfort in the oral cavity during chemotherapy are essential [21]. For the good of the children, close cooperation of the oncological team with a pediatric dentist and school nurse is indispensable.

It would be useful if a fluoride prevention program [23] in the time of remission were applied. The results of this examination indicate that a preventative therapy was in fact implemented sporadically. What helped improve the hygiene condition of the adult patients after a marrow transplant was professional hygienic preventative measures and weekly examinations, which resulted in a far lower frequency of mucositis symptoms occurrence [31]. Teaching children tooth brushing and advising parental supervision until the child is 7 during the teeth brushing was also very efficient [32].

The necessity of access to both dental care and prompt treatment after diagnosing changes in the patients of the children's oncology ward are emphasized by Nemeth et al. [25, 33], as well as Mercier et al. [34].

The survey results show that a fairly low percentage of children (9\%) use water to quench thirst [35]. Probably in view of the child's condition treated in the oncology ward, parents allow them to drink sweet drinks, which has also been noted by other authors [25, 33], especially in the period of lower saliva secretion to lessen the symptoms of dryness in the oral cavity.

The high percentage of the patients who consume sweet drinks reflects the unhealthy food habits in the remaining part of the healthy society, since Poland takes $16^{\text {th }}$ place in the number of sugar-sweetened drinks purchased per capita [36] against the WHO recommendations to reduce sugar consumption added to food to less than $10 \%$ of the overall energy consumption [37]. It is worth noting that 5 years after a patient is cured, $70 \%$ more calories than is recommended in the diet of those cured comes from simple sugars [38].

The Change4life application created by Public Health England [39] may be a helpful tool for parents to estimate the sugar content in drinks and food taken by children during chemotherapy. It allows scanning of bar codes on food packaging, which enables parents and guardians to check the amount of sweeteners used in children's food.

\section{CONCLUSIONS}

In the light of the present results, it seems necessary to undertake further systemic measures with a view to improving the oral hygiene condition of children undergoing cancer therapy and the education level of parents on the subject of a diet that should be applied in this difficult period where cariogenic products would be eliminated.

\section{ACKNOWLEDGMENTS}

This work was supported by statutory sources KNW1-103/N/4/O from the Medical University of Silesia. There are no conflicts of interest to declare.

\section{CONFLICT OF INTEREST}

The authors declare no potential conflicts of interest with respect to the research, authorship, and/or publication of this article.

\section{References}

1. Kowalczyk JR. Wprowadzenie do onkologii i hematologii dziecięcej. Skrypt dla lekarzy specjalizujących się w onkologii i hematologii dziecięcej. Warszawa: CMKP; 2011 [In Polish].

2. Wojciechowska U, Czaderny K, Ciuba A, Olasek P, Didkowska J. Nowotwory złośliwe w Polsce w 2016. Warszawa: Centrum Onkologii - Instytut im. Marii Skłodowskiej-Curie; 2018 [In Polish].

3. Boman KK, Kjällander Y, Eksborg S, Becker J. Impact of prior traumatic life events on parental early stage reactions following a child's cancer. PLoS One 2013; 8: 57556.

4. Hedén L, Pöder U, von Essen L, Ljungman G. Parents' perceptions of their child's symptom burden during and after cancer treatment. J Pain Symptom Manage 2013; 46: 366-375.

5. Wikman A, Hovén E, Cernvall M, Ljungman G, Ljungman L, von Essen L. Parents of children diagnosed with cancer: work situation and sick leave, a five-year post end-of-treatment or a child's death follow-up study Acta Oncologica 2016; 55: 1152-1157.

6. den Hoed MAH, Lopez-Lopez E, te Winkel ML, et al. Genetic and metabolic determinants of methotrexate-induced mucositis in pediatric acute lymphoblastic leukemia. Pharmacogenomics J 2015; 15: 248-254.

7. Holmboe L, Andersen AM, Mørkrid L, Slørdal L, Hall KS. High dose methotrexate chemotherapy: pharmacokinetics, folate and toxicity in osteosarcoma patients. Br J Clin Pharmacol 2012; 73: 106-114. 
8. Mendonça RM, Araújo Md, Levy CE, et al. Oral mucositis in pediatric acute lymphoblastic leukemia patients: evaluation of microbiological and hematological factors. Pediatr Hematol Oncol 2015; 32: 322-330

9. Ribeiro ILA, Limeira RRT, Dias de Castro R, Ferreti Bonan PR, Valença AMG. Oral mucositis in pediatric patients in treatment for acute lymphoblastic leukemia. Int J Environ Res Public Health 2017; 14: 1468.

10. Kumar J, Singh A, Seth R, Xess I, Jana M, Kabra SK. Prevalence and predictors of invasive fungal infections in children with persistent febrile neutropenia treated for acute leukemia - a prospective study. Indian J Pediatr 2018; 85: 1090-1095.

11. Kebudi R, Kizilocak H. Febrile neutropenia in children with cancer: approach to diagnosis and treatment. Curr Pediatr Rev 2018; 14: 204-209.

12. Löe H. The Gingival Index, the Plaque Index and the Retention Index Systems. J Periodont 1967; 38: 610-616.

13. Greene JC, Vermillion JR. The simplified oral hygiene index. J Am Dent Assoc 1964; 68: 7-13.

14. Pels E, Mielnik-Błaszczak M. Oral hygiene in children suffering from acute lymphoblastic leukemia living in rural and urban regions. Ann Agric Environ Med 2012; 19: 529-533.

15. Olczak-Kowalczyk D, Daszkiewicz M, Adamowicz-Klepalska B, et al. Status of oral hygiene and dentition in children exposed to anticancer treatment. Ann Diagn Paediatr Pathol 2004; 8: 99-106.

16. Venkataraghavan K, Majithia U, Choudhary P, Trivedi K, Shah S. Relationship between oral health status and hematological values in pediatric leukemic patients: an evaluative survey. J Contemp Dent Pract 2014; 15: 614-617.

17. Bardellini E, Amadori F, Majorana A. Oral hygiene grade and quality of life in children with chemotherapy-related oral mucositis: a randomized study on the impact of a fluoride toothpaste with salivary enzymes, essential oils, proteins and colostrum extract versus a fluoride toothpaste without menthol. Int J Dent Hyg 2016; 14: 314-319.

18. Doss LM, Dandoy CE, Kramer K, et al. Oral health and hematopoietic stem cell transplantation: a longitudinal evaluation of the first 28 days. Pediatr Blood Cancer 2018; 65. DOI: 10.1002/ pbc. 26773.

19. Ponce-Torres E, del Socorro Ruíz-Rodríguez M, Alejo-González F, Hernández-Sierra JF, de J Pozos-Guillén A. Oral manifestations in pediatric patients receiving chemotherapy for acute lymphoblastic leukemia. J Clin Pediatr Dent 2010; 34: 275-279.

20. Morais EF, Lira JA, Macedo RA, Santos KS, Elias CT, Morais Mde L. Oral manifestations resulting from chemotherapy in children with acute lymphoblastic leukemia. Braz J Otorhinolaryngol 2014; 80: 78-85

21. Xavier AM, Hegde AM. Preventive protocols and oral management in childhood leukemia - the pediatric specialist's role. Asian Pac J Cancer Prev 2010; 11: 39-43.

22. Glenny AM, Gibson F, Auld E, et al. Children's Cancer and Leukaemia Group (CCLG)/Paediatric Oncology Nurses Forum's (CCLG-PONF) Mouth Care Group. The development of evidence-based guidelines on mouth care for children, teenagers and young adults treated for cancer. Eur J Cancer 2010; 46: 1399-1412.

23. Karolewska E, Konopka T. Algorytm stomatologicznego postępowania profilaktyczno-leczniczego u dzieci z białaczkami. Czas Stomat 2006; 59: 245-252.

24. Antunes HS, Ferreira EM, de Faria LM, et al. Research Streptococcal bacteremia in patients submitted to hematopoietic stem cell transplantation: the role of tooth brushing and use of chlorhexidine. Med Oral Patol Oral Cir Bucal 2010; 15: 303-309.

25. Nemeth O, Hermann P, Kivovics P, Garami M. Long-term effects of chemotherapy on dental status of children cancer survivors. Pediatr Hematol Oncol 2013; 30: 208-215.

26. Szyszkowska A, Puławska M, Lewicka M, Koper J, Malicka M. Dental care of patients undergoing chemo- and radiotherapy. Contemp Oncol 2011; 15: 102-106.
27. Padmanabhan MY, Pandey RK, Kumar A, Radhakrishnan A. Dental management of a pediatric patient with Burkitt lymphoma: a case report. Spec Care Dentist 2012; 32: 118-123.

28. Craig JV, Gibson F, Glenny AM. Audit to monitor the uptake of national mouth care guidelines for children and young people being treated for cancer. Support Care Cancer 2011; 19: 1335-1341.

29. Barbosa AM, Ribeiro DM, Caldo-Teixeira AS. Knowledge and practices of oral health on hospitalized children with cancer. Cien Saude Colet 2010; 15 Suppl 1: 1113-1122.

30. Lauritano D, Petruzzi M. Decayed, missing and filled teeth index and dental anomalies in long-term survivors leukaemic children: a prospective controlled study. Med Oral Patol Oral Cir Bucal 2012; 17: 977-980

31. Kashiwazaki H, Matsushita T, Sugita J, et al. Professional oral health care reduces oral mucositis and febrile neutropenia in patients treated with allogeneic bone marrow transplantation. Support Care Cancer 2012; 20: 367-373.

32. Levin L, Bilder L, Borisov O. Improving oral hygiene skills among children undergoing treatment at the haemato-oncology department - an interventional programme. Int Dent J 2015; 65: 211-215.

33. Nemeth O, Kivovics M, Pinke I, Marton K, Kivovics P, Garami M. Late effects of multiagent chemotherapy on salivary secretion in children cancer survivors. J Am Coll Nutr 2014; 33: 186-191.

34. Mercier M, Bocquet E, Danguy M, Rousset MM. Planning dental care and orthodontic treatment for children afflicted with malignant hematological diseases. Orthod Fr 2011; 82: 299-306 [Article in French].

35. Olczak-Kowalczyk D, Jackowska T, Czerwionka-Szaflarska M, Książyk J, Szostak-Węgierek D, Kaczmarek U. Stanowisko polskich ekspertów dotyczące zasad żywienia dzieci i młodzieży $\mathrm{w}$ aspekcie zapobiegania chorobie próchnicowej. Borgis - Nowa Stomatologia 2015; 2: 81-90 [In Polish].

36. Popkin BM, Hawkes C. Sweetening of the global diet, particularly beverages: patterns, trends, and policy responses. Lancet Diabetes Endocrinol 2016; 4: 174-186.

37. World Health Organization. Guideline: sugars intake for adults and children. Geneva: WHO; 2015. Available at: https://www. who.int/publications/i/item/9789241549028.

38. Tylavsky FA, Smith K, Surprise H, et al. Nutritional intake of longterm survivors of childhood acute lymphoblastic leukemia: evidence for bone health interventional opportunities. Pediatr Blood Cancer 2010; 55: 1362-1369.

39. Sugar: pushing forward on cutting back. Lancet Diabetes Endocrinol 2016; 4: 85 